\title{
MANUAL DE IDENTIFICAÇÃO DE ARANHAS DE IMPORTÂNCIA MÉDICA LOXOSCELES E PHONEUTRIA - CAMPUS URBANOVA/SJC/SP
}

\author{
Suzanne Santos Toledo ${ }^{1}$ \\ Karla Andressa Ruiz Lopes ${ }^{2}$ \\ Nádia Maria Rodrigues de Campos Velho ${ }^{3}$
}

\begin{abstract}
Resumo: As aranhas estão presentes em diversos ambientes e com hábitos sedentários. A cidade de São José dos Campos, SP, possui registros de acidentes de importância médica por araneísmo, principalmente pelos gêneros Loxosceles e Phoneutria. O presente trabalho teve como objetivo a elaboração de um manual básico para auxilio de identificação das principais estruturas de aranhas de importância médica. As seguintes estruturas foram identificadas e fotodocumentadas: queliceras, olhos, cribelo (ausência), lábio, pulmões, unhas, palpo, e carapaça. Os registros permitiram distinguir duas famílias de aranhas. Conclui-se que a elaboração de um manual para auxiliar a identificação de espécimes de aranhas é extremamente útil para o reconhecimento de diferentes familias.
\end{abstract}

Palavras-chave: Mata Atlântica; Artrópodes; Aracnofauna; Araneísmo.

\footnotetext{
${ }^{1}$ Ciências Biológicas/Universidade do Vale do Paraíba, Brasil. E-mail: suzanne.santossjc@gmail.com.

2 Ciências Biológicas/Universidade do Vale do Paraíba, Brasil. E-mail: karla@univap.br.

${ }^{3}$ Ciências Biológicas/Universidade do Vale do Paraíba, Brasil. E-mail: nvelho@univap.br.
} 